\title{
¿La política construye el Reino de Dios?*
}

\section{Does Politics Build God's Kingdom?}

\author{
José de Jesús Godínez Terrones**
}

Recibido: 3 de abril de 2016

Aprobado: 24 Agosto de 2016

Disponible en línea: 30 de enero de 2017

\section{Resumen}

Jesús trae la Buena Noticia, todos somos hijos de Dios e invita a trabajar en la construcción de su reino. La primitiva Iglesia y la contemporánea consideran que ha de comenzar a construirse aquí y ahora. Dos visiones de política radicalmente opuestas se presentan, la de Aristóteles y la de John Rawls. Ambas buscan con las herramientas políticas construir una sociedad de acuerdo con las premisas establecidas por ellos. Rawls y Aristóteles reflexionan sobre la ética y la política desde la filosofía. En Aristóteles, la dimensión comunitaria forma parte de la naturaleza humana. La felicidad y la virtud son los motores de la acción ciudadana. En Rawls, la sociedad está conformada por personas con intereses muy diferentes, quienes, para conseguir sus propios fines, realizan un contrato social. El cumplimiento del contrato mueve a los ciudadanos a la cooperación para una vida mejor. Es la

\section{Abstract}

Jesus brings the Good News, we are all children of God and invites us to work on building his Kingdom. The early Church and the contemporary one consider it must start to be built here and now. Two diametrically opposed political visions are presented, Aristotle's and J. Rawls's, both seeking with political tools to build a society according to the premises they established. Rawls and Aristotle reflect on ethics and politics from philosophy. In Aristotle the community dimension is part of human nature. Happiness and virtue are the engines of citizen action. In Rawls society is made up of people with very different interests, who, in order to achieve their own ends, carry out a social contract. Compliance with the contract moves citizens to cooperate for a better life. It is politics which structures a society. Therefore, building the Kingdom requires use of the political tools. Believing in

doi:10.11144/Javeriana.papo22-1.pcrd

* Artículo de Reflexión

** Doctor en Filosofía con Orientación en Ciencias Políticas por la Universidad Autónoma de Nuevo León. Profesor de la Universidad De La Salle Bajío. Correo electrónico: jjoseph94@hotmail.com. Orcid: http://orcid. org/0000-0002-3547-6979 


\section{0}

José de Jesús Godínez Terrones

política la que estructura una sociedad, por lo cual la construcción del Reino requiere hacer uso de las herramientas de la política. Creer en Jesús es construir y estructurar una sociedad que parta de la premisa de que el ser humano es hijo de Dios y de la necesidad de crear las condiciones sociales que posibiliten su desarrollo como tal.

\section{Palabras clave:}

Reino de Dios; construcción del Reino; política Reino de Dios; Iglesia política; ser humano hijo de Dios; igualdad de la condición humana

\section{Cómo citar este artículo:}

Godínez-Terrones, J. de J. (2017). ćLa política construye el Reino de Dios? Papel Político, 22(1), 59-76. https://doi.org/10.11144/Javeriana.papo22-1.pcrd
Jesus is building and structuring a society that departs from the premise that the human being is a child of God and from the need to create the social conditions to enable his/her development as such.

\section{Keywords:}

The Kingdom of God; building the Kingdom; politics kingdom of God; politics Church; Being human son of God; equality of the human condition 


\section{Introducción}

La pregunta que guía esta indagación es la siguiente: ¿̇La política construye el Reino de Dios? En este trabajo, se presentan cuatro posiciones que expresan elementos constitutivos de una sociedad, dos desde la filosofía y dos desde la religión. Se revisan el fin de la sociedad, la ley, la ética y la justicia.

Los planteamientos de Aristóteles y Rawls surgen en ámbitos distintos con siglos de distancia; ambos se originan desde un pensamiento ético, político y filosófico. Los otros dos planteamientos son el del cristianismo primigenio, que está plasmado en el Nuevo Testamento, y el de la Iglesia católica, que está plasmado en los documentos del Concilio Vaticano II y el Compendio de la doctrina social de la Iglesia. Si bien son documentos producto de una reflexión originada desde una experiencia religiosa, estructuran ideas que repercuten en la ética y la política.

Rawls y Aristóteles reflexionan sobre la ética y la política desde la filosofía. El cristianismo de los primeros años y la Iglesia católica reflexionan desde la fe sobre el Reino de Dios. Rawls no es continuador de la teoría aristotélica; son dos concepciones con siglos de distancia y circunstancia social diferente. La Iglesia católica tiene su origen en el cristianismo de los primeros años, y hay una reflexión que se ha desarrollado durante siglos. En este trabajo, no se atiende a este aspecto, sino a los planteamientos presentados como doctrina oficial.

La aproximación a los textos bíblicos es desde una experiencia latinoamericana reflexiva de las corrientes del pensamiento que plantean elementos para la construcción de una sociedad. No es una reflexión teológica, como la de Carl Schmitt, Johann Baptist Metz, Clodovis Boff o monseñor Romero, por nombrar algunos. Interpretamos la realidad desde nuestros condicionamientos y prejuicios, desde nuestra experiencia presente (Ferraris, 2004, pp. 39-45). Es una revisión desde una óptica ética, política y filosófica en una sociedad influenciada por una tradición judeocristiana.

Si bien los textos bíblicos y su interpretación rebasan con mucho el ámbito de la construcción de una sociedad, están presentes analógicamente los campos ético y político de los otros dos autores; esta hermenéutica analógica es la que ayuda a encontrar sentido a los textos (Beuchot, 2015, p. 141), en un diálogo entre la identidad y la diferencia, manteniendo su identidad, pero sin perder la semejanza (Beuchot, 2014, p. 52). Los dos primeros planteamientos son una reflexión desde la fe; los de Rawls y Aristóteles son desde la reflexión filosófica, pero ambos están orientados a la construcción de una sociedad.

Se presentan cuatro proyectos para construcción de una sociedad que implican una ética y una política. Estos proyectos no se entienden unívocamente, sino en forma análoga (Beuchot, 2009), como bocetos que la praxis edifica. El Reino de Dios lleva a una praxis política independiente de las cuestiones espirituales. No es la mística a la que atendemos, sino a la propuesta para construir la sociedad. 
El Reino es un proyecto que pasa, necesariamente, por lo político, pero no se limita a ello. La política es un medio para concretizar el Reino en la dimensión espacio-temporal. Es un proyecto desde la fe, es una praxis del creyente que espera ir construyendo unos cielos nuevos, una tierra nueva en el amor.

\section{El cristiano y la construcción del Reino de Dios}

Reflexionar sobre la experiencia de la fe en un Dios, en el contexto de nuestra sociedad latinoamericana, nos lleva al cristianismo, al Jesús que les pregunta a sus discípulos ¿quién dicen que soy yo? Tú eres el Mesías (Mc 8, 29), el Ungido, el que fue crucificado, sepultado y resucitó al tercer día (1 Co 151-154). El que enseña a dirigirse a Dios como Padre: santificado sea tu Nombre, que venga tu Reino (Lc 11, 2). El que dice que todos somos hermanos, nuestro Padre es Dios (Mt 23, 8-9). El que anuncia la venida del Reino de Dios e invita a creer en la Buena Noticia (Mc 1, 15).

Jesús es el enviado a "llevar Buena Noticia a los pobres, a anunciar la liberación a los cautivos y la vista a los ciegos, a dar la libertad a los oprimidos y proclamar un año de gracia del Señor" (Lc 4, 18-19). Un Reino dado en herencia donde al hambriento le dieron de comer, al sediento le dieron de beber, al que estaba de paso lo alojaron, al desnudo lo vistieron y al enfermo y al preso lo visitaron (Mt 25, 34-46).

Jesús es quien proclama que en el Reino son dos los mandamientos, "el Señor nuestro Dios es el único Señor; y tú amarás al Señor, tu Dios, con todo tu corazón y con toda tu alma, con todo tu espíritu y con todas tus fuerzas. El segundo es: amarás a tu prójimo como a ti mismo. No hay otro mandamiento más grande que estos” (Mc 12, 29, 3).

¿Cuándo llegará el Reino de Dios? "El Reino de Dios no viene ostensiblemente y no se podrá decir: "Está aquí" o "Está allí”. "Porque el Reino de Dios está entre ustedes" (Lc 17, 20-21). El Reino se parece a un sembrador que sale a sembrar, unas semillas caen en espinos, otras en el camino, otras en tierra fértil y dan frutos (Mt 13, 1-8). Otra imagen es la de un sembrador que pone semilla buena en tierra fértil, pero el enemigo en la noche derrama cizaña, al madurar el trigo se separa la cizaña del trigo (Mt 13, 2430). El Reino también es como un grano de mostaza pequeño que se convierte en un arbusto grande. Es como un poco de levadura mezclada en una gran cantidad de harina, hasta que fermenta toda la masa (Mt 13, 31-33).

El Reino se asemeja a un negociante que se dedica a buscar perlas finas, y al encontrar una de gran valor, vende todo lo que tiene y la compra (Mt 13, 45-46). Es un tesoro escondido en un campo, un hombre lo encuentra, lo vuelve a esconder y, lleno de alegría, vende todo lo que posee y compra el campo (Mt 13, 44). Es como una red que se echa al mar y recoge toda clase de peces. Cuando está llena, los pescadores la sacan a la orilla y, sentándose, recogen lo bueno en canastas y tiran lo que no sirve (Mt 13, 47-48). 
El Reino es similar a un banquete al que hemos sido invitados (Mt 22, 1-14). El discípulo del Reino es como un dueño de casa que saca de sus reservas lo nuevo y lo viejo (Mt 13, 52), el amor de Dios en su nueva expresión, la de hijos, que actúan como tales, que no solo buscan cumplir la ley, sino lo más importante de la ley: la justicia, la misericordia y la fe (Mt 23, 23).

Jesús anuncia la venida del Reino de Dios, que no tiene un espacio físico delimitado, "Está aquî" o "Está allí”, sino "entre ustedes", alude a una relación de personas, a las condiciones de interacción personal. Es una nueva forma de relacionarse las personas entre sí, es partir de una condición de igualdad ante el otro. Es una Buena Noticia que puede ser aceptada o no por las personas. Es una semilla que genera frutos, son acciones que posibilitan su expansión. El Reino tiene un valor absolutizante, todo es relativo en función de él, es lo más preciado y se está dispuesto a desposeerse de todo por el Reino. Implica un cernir lo bueno y lo malo, deshacerse de lo malo y quedarse con lo bueno, sacar de las reservas lo bueno y lo viejo.

El Reino implica un compromiso personal totalizante, es tan precioso y atrayente que todo lo demás está en función de él. Son acciones que impulsan resultados en el entorno, que permiten separar lo bueno de lo malo. El Reino es un modo de vida en el que se separan los frutos buenos de los malos, los frutos buenos son aquellos que han generado una relación de solidaridad con el otro, con el prójimo necesitado; pero no solo eso, sino una actitud promovente de la justicia, del bien del otro, un impulso para hacer de las relaciones con los otros un banquete en el que todos estamos invitados a participar bajo la misma condición, como hijos. Es la igualdad de la condición humana, el punto de partida de la justicia.

La primitiva Iglesia consideró que una forma de vivir el Reino es llevar una vida en común, en la fracción del pan y en las oraciones, mantenerse unidos, poner las propiedades en común, vender las propiedades y bienes, distribuir el dinero según las necesidades de cada uno (Hch 2, 42-47). Que no hubiera necesidad entre ellos, ponían el dinero a disposición de los Apóstoles para que lo distribuyeran a cada uno según sus necesidades (Hch 4, 33-37).

La cooperación no se da solo en una comunidad, sino entre comunidades. Los miembros de la comunidad de Antioquía envían ayuda a sus hermanos de Judea, cada uno según sus posibilidades por intermedio de Bernabé y Saulo (Hch 11, 27-30). Esto mismo sucede en las comunidades de Corinto y Galacia (1 Co 16, 1-3).

El cristianismo no es una doctrina, es una forma de vida. ¿De qué le sirve a uno, hermanos míos, decir que tiene fe, si no tiene obras? ¿Acaso esa fe puede salvarlo? La fe, si no va acompañada de las obras, está completamente muerta. "Muéstrame, si puedes, tu fe sin las obras. Yo, en cambio, por medio de las obras, te demostraré mi fe" (St 2, 14-18).

Creer no es una actitud pasiva ni contemplativa, es un actuar. Es mostrar que se actúa conmigo mismo y con el otro promoviendo la justicia, que parte de la misma condición de 
igualdad, hijo de Dios. La fe es en Jesús, a los que creen en su Nombre, les dio el poder de llegar a ser hijos de Dios (Jn 1, 12). Por lo que creer en Jesús es actuar como hijo de Dios, creer es actuar. Por lo que, ya no hay judío ni pagano, esclavo ni hombre libre, varón ni mujer, porque todos ustedes no son más que uno en Cristo Jesús (Ga 3, 26-28).

Ser cristiano es transformar las relaciones sociales, romper el estatus de superioridad o inferioridad, es construir una sociedad más igualitaria, que parta de la igualdad de la condición humana, hijos de Dios, amo y esclavo es una relación de superioridad e inferioridad. Dios infundió en nuestros corazones el Espíritu de su Hijo, que clama a Dios llamándolo iAbba!, es decir, iPadre! Esa es la Buena Noticia, el amor de Dios, somos hijos de Dios, esa es la gracia, el regalo de Dios, es la herencia del Padre. Así, ya no eres más esclavo, sino hijo y, por tanto, heredero por la gracia de Dios (Ga 4, 6-7). Es el nuevo estatus del cristiano, hijo de Dios, dar testimonio de que somos hijos de Dios. Si somos hijos, también somos herederos, herederos de Dios y coherederos de Cristo, porque sufrimos con él para ser glorificados con él (Rm 8, 16-17). Ser cristiano es actuar, dar testimonio de ser hijo de Dios. Es considerar al otro en la misma condición de dignidad humana, no superior ni inferior, igual.

La fe es actuar, dar testimonio de la Buena Noticia, conservar la seguridad y la esperanza de la herencia prometida ( $\mathrm{Hb} 3,5-6)$. La promesa de la herencia es concedida por la fe, Abraham creyó en "el Dios que da vida a los muertos y llama a la existencia a las cosas que no existen”, y su promesa le fue cumplida, él esperó contra toda esperanza ( $R m$ 4, 12-18).

Dios cumple su promesa, es una certeza que genera la fe. "Feliz de ti por haber creído que se cumplirá lo que te fue anunciado de parte del Señor” (Lc 1, 45), dice Isabel cuando María la visita. Simeón, al ver a Jesús, exclama: “Ahora, Señor, puedes dejar que tu servidor muera en paz, como lo has prometido, porque mis ojos han visto la salvación" (Lc 2, 29-32). La esperanza se sustenta en que quien hizo la promesa es fiel (Hb 10, 23), es el Dios que se manifiesta en Jesús cuando lo resucita (Ef 1, 17-20). Por lo que creer en Jesús es actuar esperando recibir la gracia de Dios (1 P 1, 12-13).

La esperanza es un construir para el Reino. La esperanza no es un modo de ser pasivo, es un actuar continuo. Se espera por la fe recibir los bienes de la justicia del Reino, la "fe que obra por medio del amor" (Ga 5, 4-6). La fe, la esperanza y el amor son tres aspectos diferentes del actuar del cristiano. "En una palabra, ahora existen tres cosas: la fe, la esperanza y el amor, pero la más grande de todas es el amor" (1 Co 13, 13), porque creo, espero amando.

Creer en Jesús es actuar, confiar que cumple lo que promete, un Reino de justicia, que el cristiano está construyendo. Esperar el Reino es trabajar para el Reino, es un obrar en el amor. La fe en Jesús lleva a esperar un Reino que se está construyendo en el aquí y en el ahora, creando relaciones, estructuras sociales, que permitan vivir la justicia y el amor. 
El creer es un actuar, dar testimonio de ser hijo de Dios, amar a tu prójimo como a ti mismo (Ga 5, 14), es construir una relación sustentada en que el otro es hijo de Dios, es aceptar la herencia de Dios, la filiación, ser hijos de Dios. Ya somos hijos de Dios, pero todavía no hemos terminado de construir una relación como tales, todavía falta la plenitud del Reino, es el ya pero todavía no.

Esperamos el Reino de Dios construyéndolo en la relación fraterna. Creo actuando, espero construyendo, amo actuando con el otro como actuaría conmigo mismo, actúo con el otro como hijo de Dios. La tarea del cristiano es ¿cómo construir una relación igualitaria con el otro? ¿Cómo construir el Reino? ¿Cómo generar las condiciones para que se realice el mandato de amar al prójimo como a ti mismo?

\section{La Iglesia y la construcción del Reino de Dios en la sociedad}

En diferentes documentos, la Iglesia católica expresa su posición en la construcción del Reino. La promesa de Dios de un Reino en el que habita la justicia suscita la esperanza en los cristianos por construir esa morada nueva (Pontificio Consejo "Justicia y Paz", 2005, p. 56), en la que las relaciones entre las personas estén encaminadas a mejorar el mundo, en la paz y en la justicia (p. 58). El cristiano es un solidario con los más desvalidos, débiles de la sociedad. "Los gozos y las esperanzas, las tristezas y las angustias de los hombres de nuestro tiempo, sobre todo de los pobres y de cuantos sufren, son a la vez gozos y esperanzas, tristezas y angustias de los discípulos de Cristo" (Gaudium et spes, 1). En su peregrinar hacia el Reino del Padre, la Iglesia, la comunidad cristiana, se siente solidaria con el género humano y su historia. Para que la humanidad pueda “establecer un orden político, económico y social que esté más al servicio del hombre y permita a cada uno y a cada grupo afirmar y cultivar su propia dignidad" (9).

La construcción del orden social es una tarea cotidiana, que implica la renovación de los espíritus y profundas reformas a la sociedad, procesos sustentados en la verdad, la justicia, el amor, para conseguir con libertad un equilibrio acorde con el ser humano (26). Una sociedad que parta de la igualdad fundamental de todos los hombres.

Una sociedad en la que "toda forma de discriminación en los derechos fundamentales de la persona, ya sea social o cultural, por motivos de sexo, raza, color, condición social, lengua o religión, debe ser vencida y eliminada por ser contraria al plan divino" (29). Construir una nueva comunidad fraterna cuya ley sea el amor, en la que sus miembros deben ayudarse mutuamente según las capacidades de cada uno de ellos (32).

El mensaje cristiano plantea como deber la edificación del mundo conforme al bien del género humano y que permita al ser humano como individuo y miembro de la sociedad desarrollarse como persona (34-35). Construyendo una comunidad fraterna que siga el mandamiento del amor, no en las cosas extraordinarias, sino en la vida cotidiana (38). A fin de conseguir un "Reino de verdad y de vida; Reino de santidad y 
gracia; Reino de justicia, de amor y de paz" (39), sin confundir que el progreso temporal significa el crecimiento del Reino, aunque el primero, el progreso, puede contribuir a que la sociedad humana se encamine a la consecución del Reino.

La Iglesia colabora con todas las instituciones que permitan conseguir su misión, no importa el régimen político en cuanto respeten los derechos fundamentales de la persona, la familia y los imperativos del bien común (42). La Iglesia "solo pretende una cosa: el advenimiento del Reino de Dios y la salvación de toda la humanidad” (45). La Iglesia busca activamente la solución a los complejos y variados problemas, como son "el matrimonio y la familia, la cultura humana, la vida económico-social y política, la solidaridad de la familia de los pueblos y la paz" (46).

Transformar las relaciones sociales, según las exigencias del Reino de Dios, es una tarea continua para la comunidad cristiana que se ha de realizar reflexionando y con la praxis inspirada en el Evangelio (Pontificio Consejo “Justicia y Paz”, 2005, p. 53). El anuncio de que Dios es amor, es el amor lo que ha de regir las relaciones entre los seres humanos, el amor es "la ley fundamental de la perfección humana, y, por tanto, de la transformación del mundo" (p. 54).

Es la comunidad cristiana, la Iglesia, el sacramento, el signo visible del amor de Dios, la esperanza de la realización del proyecto de una auténtica liberación y promoción humana, en el contexto histórico y del mundo concreto en el que se vive el ser humano. Es la respuesta al proyecto del Reino (p. 6o). Actuar en la compleja red de relaciones sociales, para fecundar y fermentar la sociedad con el Evangelio (p. 62). "Unos cielos y una nueva tierra, edificar una sociedad reconciliada y armonizada en la justicia y en el amor" (p. 82). Generar cambios en las estructuras sociales que nos posibiliten esta condición.

La reflexión que la Iglesia hace sobre la sociedad va encaminada a que los cristianos se comprometan a construir, organizar y hacer funcionar una sociedad, con obligaciones políticas, económicas y administrativas que promuevan la justicia (p. 83). El objetivo es continuar con la Buena Nueva que "la humanidad se hiciera familia de Dios, en la que la plenitud de la ley sea el amor" (Gaudium et spes, 32). Una sociedad que parta de la premisa de que todos somos hijos de Dios, y una sociedad estructurada que permita el desarrollo de todos como tales.

\section{La política y la construcción de la sociedad}

El ser humano se relaciona con otros en una comunidad, la comunidad apunta hacia algún bien, en la comunidad el ser humano aspira a conseguir el máximo bien. La comunidad suprema por la que se aspira al máximo bien es lo que se denomina ciudad, la polis, que es la comunidad política (Aristóteles, 1985, p. 157). El hombre por esencia es un animal de la polis. Un ser que se relaciona con los otros en una comunidad. La polis es, por esencia, anterior al individuo. No es autosuficiente el individuo solo, su existencia 
depende de los otros hombres que viven en la ciudad. La ciudad es, asimismo, por naturaleza, anterior a la familia y a cada uno de los individuos.

La ciudad es el espacio para la complementariedad y colaboración entre sus miembros, los ciudadanos. La ciudad es un "cuerpo de ciudadanos capaz de llevar una existencia autosuficiente" (Aristóteles, 1985, p. 198). La relación del individuo con la polis es la relación del todo con las partes. No estar en esta participación por incapacidad o autosuficiencia es porque se es bestia o dios (p. 159). Quien se encuentra fuera de la polis es mal hombre, un hombre disminuido, o más que hombre. La polis es el espacio en el que el hombre desarrolla sus potencialidades en cuanto humano, es el espacio donde se dirime su devenir como miembro de una comunidad, su participación en la polis como ciudadano es algo "por naturaleza", algo esencial al ser humano.

La ciudad es una pluralidad de humanos de diferente condición que interactúan entre sí y que dan y reciben una contraprestación igualitaria, que permite que todos tengan parte de los sabores y sinsabores del poder (p. 174). Los ciudadanos participan en los diferentes puestos de la ciudad, y en un momento determinado les toca obedecer y en otro momento mandar. Los puestos de la polis no son solo para algunos, sino que todos los ciudadanos en diferentes momentos los ocupan. Un ciudadano es quien tiene derecho a participar en el poder judicial o deliberativo y en el poder político, de gobernar la ciudad (pp. 197-198).

La virtud del ciudadano: ser entendido en el gobierno de los hombres libres en un uno y otro aspecto tanto en mandar cuando tiene un cargo como en obedecer cuando no lo tiene (p. 201). El ciudadano es un ser comprometido con la polis, su actuar está en función del puesto que ocupa y como ciudadano que no ocupa un cargo. El ciudadano actúa en la polis tanto si ocupa o no un cargo.

La ciudad existe no solo por la simple vida, sino, sobre todo, por la vida mejor. La ciudad es la comunidad de familias y municipios para una vida perfecta y autosuficiente, es decir, para una vida bella y feliz. La comunidad política tiene por causa la práctica de las buenas acciones y no simplemente la convivencia (pp. 206-207). Entonces, la ciudad no solo es un aglomerado de personas, sino una comunidad que tiene como fin una vida feliz, alcanzable con la práctica de buenas acciones.

El desarrollo de la virtud y el vicio es voluntario, el sujeto es consciente, capaz de deliberar y actuar voluntariamente. La virtud constituye un modo de ser, que depende de cultivar un hábito electivo. Es fruto de la costumbre (p. 18). Es aquel hábito por el cual el hombre se hace bueno y gracias al cual realizará bien la obra que le es propia (p. 22). Reside en el término medio, pero no en términos absolutos sino relativos a nosotros, de acuerdo con el término medio al alcance de cualquier individuo (p. 231). No está en los extremos. Un extremo es defecto y otro es exceso, así entre miedo y osadía la valentía es el término medio. El término medio es determinado por la razón, como lo hiciese un hombre prudente (p. 23), desde el punto de vista de la perfección y el bien. 
La felicidad es el fin supremo de la vida humana, ya que se elige siempre por sí misma y nunca por otra cosa. Todos los fines son fines finales; pero el bien supremo debe ser evidentemente algo final, por tanto, si solo hay un fin final, este será el bien que se busca, lo absolutamente final es aquello que es apetecible siempre por sí y jamás por otra cosa, la felicidad es algo final y autosuficiente, es el fin de cuanto se hace, es lo que hace deseable la vida y que no necesita nada (pp. 8-9).

La vida feliz es la que se vive sin impedimento de acuerdo con la virtud (p. 231). El hombre feliz es el que vive bien y obra bien, la felicidad es una especie de vida dichosa y de conducta recta (p. 11), no es un estado anímico, es consecuencia de una vida virtuosa. "La felicidad consiste en el ejercicio y práctica consumada de la virtud, y esto no en sentido condicional, sino absoluto" (p. 292). Condicional es lo que es obligado y absoluto es lo que se hacer por el bien mismo.

La mejor constitución es necesariamente aquella cuyo ordenamiento permita a cualquier individuo hallarse mejor y llevar una vida más feliz (pp. 279-280). El fin último de la política y de las leyes es buscar la felicidad del ser humano. "En todas la ciencias y artes el fin es el bien; el mayor y principal es el objeto de la suprema disciplina entre todas, la política. En consecuencia el bien de la ciudad es la justicia, esto es el bienestar público" (p. 210).

La justicia es algo objetivo en relación con las personas, cierta igualdad entre los iguales y desigualdad entre los desiguales. La mejor constitución es “aquella cuyo ordenamiento permita a cualquier individuo el hallarse mejor y llevar la vida más feliz" (p. 280). Una vida ordenada por la virtud. La ciudad es virtuosa cuando lo son los ciudadanos, y las leyes de la ciudad posibilitan la virtuosidad de los ciudadanos.

La ley, en efecto, deriva solo de la costumbre de la fuerza que tiene para inducir a la obediencia, la costumbre nace en el transcurso del tiempo (p. 187). Si la fuerza de la ley deriva de la costumbre y la costumbre crea la virtud, la virtud hace al hombre feliz, entonces la ley es para crear virtudes, por lo que la política no es solo la administración de la polis. La política se sirve de las demás ciencias prácticas y legisla sobre lo que debe hacerse y lo que debe evitarse, para conseguir su fin ético, la felicidad en el seno de una comunidad autárquica (pp. 3-4).

La ley es la razón sin apetito, es imparcial, aplicada por uno o más hombres virtuosos que disciernen, que deliberan (pp. 217-218). Si en la ética se plantea que la virtud es el término medio, en la ciudad hay ricos, pobres y clase media, si se reconoce que lo moderado es lo mejor, es claro que una moderada fortuna es la mejor de todas. Obedecer a la razón en estas condiciones, de moderación, es más fácil. Los excesos, riqueza o pobreza no se dejan guiar por la razón. Por lo que la mayor fortuna para una ciudad consiste en que sus miembros posean un patrimonio suficiente y moderado. Cuando la clase media es numerosa, es ínfima la probabilidad de facciones o disensiones (pp. 
231-232). Los extremos son los que crean inestabilidad en la polis, extrema riqueza y extrema pobreza. Una fortuna moderada y suficiente da estabilidad a la polis.

La política se sirve de las demás ciencias para buscar el verdadero bien del ser humano. El bien del individuo está en coherencia con el bien de la ciudad. Es el mismo bien. Si es bello hacer el bien al individuo es más bello procurarlo para la ciudad (p. 4). De manera consecuente, la política plantea que una ciudad debe tener el territorio y la población que le permita ser autosuficiente y feliz.

Las funciones necesarias en una ciudad son seis: 1) los alimentos, necesarios para la vida; 2) los oficios que procuren instrumentos para el trabajo; 3) las armas para el ejercicio del gobierno, evitar insubordinaciones y defenderse de las agresiones externas; 4) recursos que satisfagan las necesidades; 5) el culto, el servicio divino; y 6) la decisión judicial sobre los intereses y derechos recíprocos (pp. 284-287). La ciudad ha de organizarse de acuerdo con estas funciones, debe haber una población agrícola, artesanos, militares, propietarios, sacerdotes y jueces. La política está en coherencia con la ética. Una sobre el bien de la ciudad y la otra habla sobre el bien del individuo. En ambas, el fin es la felicidad del hombre mediante la virtud, leyes que generen seres humanos virtuosos y felices.

\section{La justicia como prioridad en la construcción de la sociedad}

Rawls trata de generalizar y llevar la teoría tradicional de contrato social, representada por Locke, Rousseau y Kant, a un nivel más elevado de abstracción. La sociedad se rige por un contrato social hipotético, en la que la justicia es la primera de las instituciones sociales, la justicia es al sistema social lo que la verdad es a los sistemas de pensamiento. Si hay leyes injustas, deben ser derogadas o reformadas sin importar que las leyes e instituciones sean eficientes. En una sociedad justa, los derechos declarados por la justicia no están sujetos a regateos políticos ni al cálculo de intereses sociales, las libertades de la igualdad de ciudadanía establecidas son definitivas, no temporales (Rawls, 1985, pp. 10-20).

La cooperación social es para una vida mejor: "Una sociedad es una asociación, más o menos autosuficiente, de personas que reconocen ciertas reglas de conducta como obligatorias en sus relaciones y que en su mayoría actúan de acuerdo con ellas" (p. 20). Estas reglas promueven el bien de los participantes del sistema de cooperación. Se presenta tanto una identidad como un conflicto de intereses. Hay una identidad de intereses: la cooperación social genera una mejor vida que la alcanzada por el esfuerzo individual. Hay un conflicto de intereses: al distribuir los bienes cada quien desea el mayor beneficio. Necesario es el diseño de reglas para la obtención de beneficios como la aportación de esfuerzos y suscribir un convenio sobre los derechos y obligaciones distribuidos de forma correcta.

La idea de la cooperación social tiene tres rasgos esenciales: 
- La cooperación social es cosa distinta de la mera actividad socialmente coordinada, está guiada por reglas y procedimientos reconocidos públicamente como reguladores de la conducta de los cooperantes.

- Incluye la idea de los términos equitativos de la cooperación, términos que cada participante puede aceptar razonablemente, siempre que todos los demás los acepten de igual modo.

- Incluye la idea de ventaja racional, o de bien de cada participante. La idea de ventaja racional define lo que cada uno de los participantes considera como bien propio (Rawls, 2002, p. 29).

Los ciudadanos, libres e iguales en derechos, son responsables de sus vidas, cada cual espera que los demás adapten la concepción del bien a su esperada participación de los bienes primarios. La única restricción sobre los proyectos de vida es que esos proyectos sean compatibles con los principios públicos de la justicia (Rawls, 1996, p. 185). La estructura básica de la sociedad es el primer objeto: la justicia, una concepción contractual de la justicia, por estructura básica se entiende la manera en que las más importantes instituciones sociales encajan unas a otras en un sistema, en cómo asignan derechos y deberes fundamentales, y transforman la división de las ventajas que se obtienen mediante la cooperación social (p. 243).

Los ciudadanos logran la plena autonomía política cuando su libertad e igualdad son garantizadas por una constitución razonablemente justa, cuando las leyes y los preceptos regulan la estructura básica, cuando comprenden plenamente y confirman esta constitución y sus leyes. Cuando se ajustan, las leyes, a como lo requieren los cambios sociales, siempre movidos por sentido de la justicia y demás virtudes políticas (Habermas y Rawls, 1998, p. 107).

Una persona es feliz cuando está en vías de una realización afortunada de un proyecto racional de vida trazado en unas condiciones favorables y confía razonablemente que su proyecto puede ser llevado a cabo. Es feliz cuando sus proyectos se desarrollan bien, cuando sus más importantes aspiraciones se van realizando y cuando siente seguridad de que será duradera su buena fortuna (Rawls, 1985, p. 452). Ante todo, la felicidad tiene dos aspectos: uno, es ejecución afortunada de un proyecto racional (el inventario de actividades y propósitos) que una persona se esfuerza por realizar; y el otro, el estado de ánimo, su confianza segura, sostenida por buenas razones en que su éxito continuará. La condición de ser feliz implica un cierto logro en la acción y una racional seguridad en cuanto al resultado (p. 607).

Una sociedad está bien ordenada cuando en su diseño promueve el bien de sus miembros y cuando la regula efectivamente una concepción de la justicia. Todos y cada uno de los miembros aceptan los mismos principios de justicia, el actuar, y lo que se 
sabe de las instituciones sociales básicas es que actúan de acuerdo con esos principios. Los miembros suscriben un conjunto de principios que asignan derechos y deberes básicos que consideran ser la distribución correcta de las cargas y los beneficios de la cooperación (pp. 20-21).

Los ciudadanos tienen un sentido normalmente efectivo de la justicia, entienden y aplican los principios reconocidos de justicia y actúan según lo exige su posición en la sociedad. La idea de una sociedad bien ordenada es, a todas luces, una muy considerable idealización (Rawls, 2002, pp. 31-32).

Otros elementos por considerar en la sociedad son la coordinación, eficacia y estabilidad. Así, los planes de los individuos necesitan conjuntamente ser acoplados de forma que sus actividades resulten compatibles entre sí y puedan ser todas ejecutadas sin que las expectativas legítimas de ninguno sean gravemente dañadas. El esquema de la cooperación social tiene que ser estable: se tendrá que cumplir con él más o menos regularmente y sus reglas básicas habrán de obedecerse con voluntad. Cuando estas se infrinjan, el orden ha de restaurarse para prevenir consecutivas violaciones (Rawls, 1985, p. 22).

Justicia y sociedad son un binomio: "El objeto primario de la justicia es la estructura básica de la sociedad, el modo en que las instituciones sociales más importantes distribuyen los derechos y deberes fundamentales y determinan la división de las ventajas provenientes de la cooperación social” (p. 23). Las instituciones más importantes son la Constitución política y las principales disposiciones económicas y sociales. Así, la protección jurídica de la libertad de pensamiento y de conciencia, la competencia mercantil, la propiedad privada de los medios de producción y la familia monogámica son ejemplos de instituciones sociales importantes.

Rawls intenta formular una concepción razonable de la justicia para la estructura de una sociedad bien ordenada, aislada de otras sociedades, un sistema cerrado (pp. 24-25). La justicia como equidad es una concepción política, no una concepción general: se aplica primero a la estructura básica y entiende que esas otras cuestiones de justicia local y las cuestiones de justicia global (los llama el derecho de gentes) reclaman por méritos propios una consideración aparte (Rawls, 2002, p. 34).

La cooperación en la vida social parte de una concepción de justicia, tanto en lo que a la cooperación se refiere como a los beneficios por ella. Una posición inicial es la igualdad, es el punto de partida de la justicia como imparcialidad. Los individuos, personas libres y racionales que buscan sus intereses propios parten del principio de igualdad como origen de cualquier otro acuerdo regulatorio que puedan suscribir para la cooperación social y el establecimiento de las formas de gobierno (Rawls, 1985, p. 28).

El estado de naturaleza es a la teoría tradicional del contrato social como la posición original de igualdad a la justicia como imparcialidad. La posición original no es una situación primitiva ni corresponde a un estado de cosas históricamente real ni a una situación 
primitiva de la cultura. Es una situación puramente hipotética. Los rasgos esenciales de esta situación es que nadie sabe cuál es su lugar en la sociedad, estatus social o su clase; tampoco cuál es su suerte en cuanto a la distribución de capacidades y ventajas que la naturaleza le da, como inteligencia, fortaleza.

Los propios miembros del grupo no conocen sus concepciones acerca del bien, ni sus tendencias psicológicas especiales. Los principios se escogen tras un velo de ignorancia. Al no conocer la distribución azarosa de las circunstancias sociales y naturales, se pacta un acuerdo con principios justos para todos. Se parte de una simetría en las partes, de una situación equitativa de personas como entes morales, racionales con fines propios, que poseen un sentido de justicia y mutuamente desinteresados. El concepto de racionalidad se ha de interpretar en el sentido estrictamente tradicional de la teoría económica, según la cual para conseguir un fin se emplean los medios más efectivos (pp. 29-31).

Los acuerdos fundamentales, imparciales desde la posición original, son dos: igualdad al repartir los deberes y derechos básicos; el otro es, si hay desigualdad es para producir un mayor beneficio para todos y en especial para los menos aventajados miembros de la sociedad (pp. 32-35).

La justicia como imparcialidad es una teoría deontológica, se supone que las personas en la posición original escogen el principio de libertad y restringen las desigualdades económicas y sociales en interés de todos, no hay razón para pensar que las instituciones justas maximizan el bien, no es su finalidad. Obtener el máximo bien no es un principio en la justicia como imparcialidad. Los miembros adecúan sus concepciones de bien a lo que ordenan los principios de la justicia (pp. 48-49).

La fidelidad y obediencia a los principios son útiles para mantener el orden social (p. 53). John Rawls, con su contribución a la filosofía política liberal, construye una teoría de la justicia basada en los principios del contractualismo y la posición original, que si en algo ha de beneficiar ha de ser a los menos favorecidos de la sociedad. Los ciudadanos aplican los principios reconocidos de justicia y actúan según lo exige su posición en la sociedad. La teoría de la justicia es para conseguir una sociedad ordenada conformada por una pluralidad de personas con intereses diferentes.

\section{El Reino y la política}

Jesús es enviado a llevar la Buena Noticia a los pobres, anunciar la liberación a los cautivos y la vista a los ciegos, dar la libertad a los oprimidos y proclamar un año de gracia del Señor. El cristiano es hijo de Dios y se dirige a El como Padre. Jesús invita a construir el Reino de Dios, dos los mandamientos. El primero, el Señor nuestro Dios es el único Señor; y tú amarás al Señor, tu Dios, con todo tu corazón y con toda tu alma, con todo tu espíritu y con todas tus fuerzas. El segundo, amarás a tu prójimo como a ti mismo. No hay otro mandamiento más grande que estos. 
El estatus del cristiano es de hijo de Dios y el del prójimo es el de hermano. En una sociedad tan jerarquizada como la romana, es una idea desestabilizadora del estatus, es una irrupción del orden piramidal, ya no hay judío ni pagano, esclavo ni hombre libre. Ser cristiano es transformar las relaciones sociales, romper los estatus de superioridad o inferioridad, es construir una sociedad más igualitaria.

El cambio no solo es en la sociedad sino en la misma comunidad, procuraban que no hubiera necesidad entre ellos, ponían el dinero a disposición de los Apóstoles para que lo distribuyeran a cada uno según sus necesidades. La fe en Jesús lleva a esperar un Reino que se está construyendo en el aquí y en el ahora, creando relaciones, estructuras sociales, que permitan vivir la justicia y el amor.

La Iglesia en el Vaticano II considera que los gozos y las esperanzas, las tristezas y las angustias de los hombres de nuestro tiempo, sobre todo de los pobres y de cuantos sufren, son a la vez gozos y esperanzas, tristezas y angustias de los discípulos de Cristo. La Iglesia es solidaria con el género humano para que se pueda establecer un orden político, económico y social que esté más al servicio del hombre, que permita a cada uno y a cada grupo afirmar y cultivar su propia dignidad.

Construir una nueva comunidad fraterna cuya ley sea el amor, en la que sus miembros deben ayudarse mutuamente según las capacidades de cada uno de ellos. La Iglesia es el signo visible del amor de Dios, la esperanza de la realización del proyecto de una auténtica liberación y promoción humana, en el contexto histórico y del mundo concreto en el que se vive el ser humano. Busca edificar una sociedad reconciliada y armonizada en la justicia y en el amor, unos cielos nuevos y una nueva tierra.

En Aristóteles, el ser humano se relaciona con otros en una comunidad, la comunidad apunta hacia algún bien, en la comunidad el ser humano aspira a conseguir el máximo bien. La comunidad es la ciudad, la polis, que es la comunidad política. La ciudad existe, no solo por la simple vida, sino, sobre todo, por la vida mejor. La ciudad es la comunidad para una vida perfecta y autosuficiente, es decir, para una vida bella y feliz, para la práctica de las buenas acciones y no simplemente la convivencia.

La política se sirve de las demás ciencias prácticas y legisla sobre lo que debe hacerse y lo que debe evitarse, para conseguir su fin ético, la felicidad en el seno de una comunidad autárquica. La política busca el verdadero bien del ser humano. El bien del individuo está en coherencia con el bien de la ciudad. Es el mismo bien. La política está en coherencia con la ética. Una habla sobre el bien del individuo y la otra sobre el bien de la ciudad. En ambas, el fin es la felicidad del hombre mediante la virtud, leyes que generen seres humanos virtuosos y felices.

En Rawls, la sociedad está conformada por personas con intereses muy diferentes, que para conseguir sus propios fines han de cooperar. La cooperación social es para una vida mejor. Una sociedad es una asociación, más o menos autosuficiente, de personas 
que reconocen ciertas reglas de conducta como obligatorias en sus relaciones y que en su mayoría actúan de acuerdo con ellas.

Una sociedad está bien ordenada cuando en su diseño promueve el bien de sus miembros y cuando la regula efectivamente una concepción de la justicia. Todos y cada uno de los miembros aceptan los mismos principios de justicia, el actuar, y lo que se sabe de las instituciones sociales básicas es que actúan de acuerdo con esos principios. La persona es feliz cuando sus proyectos se desarrollan bien, cuando sus más importantes aspiraciones se van realizando y cuando siente seguridad de que será duradera su buena fortuna.

La construcción de una sociedad es una propuesta presente en las cuatro posiciones. La del cristianismo y la doctrina oficial de la Iglesia concuerdan en cuanto origen, fin y medios. Los términos difieren, hay un mismo mensaje, el Reino de Dios trasciende su construcción histórica, se da en la dimensión espacio-temporal, pero no queda acotado a esta dimensión. Cada sociedad instrumentaliza este proyecto, pero ninguna puede proclamar ser el Reino, son una mediación del Reino, es un ideal por realizar, por concretizarse sin quedar agotado en esa concretización. El Reino de Dios es una metáfora que solo se comprende como sentido (Ricoeur, 1980, p. 102), con apertura a múltiples interpretaciones. Es un proyecto desde la fe en un Dios que irrumpe en la historia, pero la trasciende. Los planteamientos de Rawls y Aristóteles son proyectos desde los anhelos del ser humano por ser feliz en una sociedad justa y ordenada.

En Rawls, el cumplimiento del contrato mueve a los ciudadanos a la cooperación para una vida mejor. En Aristóteles, es la felicidad y la virtud el motor de la acción ciudadana. En los documentos de la Iglesia y del Nuevo Testamento, es la fe que espera amando lo que mueve al creyente para la construcción de la sociedad.

La felicidad en Aristóteles es una vida dichosa, que practica la virtud. En Rawls, ocurre cuando hay la realización de un proyecto racional y la seguridad de que continuará. En el cristianismo y los documentos de la Iglesia, es el regalo de Dios, la herencia del Padre, vivir el amor de Dios como hijos, unos cielos nuevos, una tierra nueva, esa es la gracia. El cristianismo plantea una realización que se presenta en la dimensión espacio-temporal, pero que no queda agotada en ella, hay una ideal que trasciende esta mediación.

En Aristóteles, la ley está encaminada a que los miembros de la comunidad consigan la felicidad en una sociedad. En Rawls, es la expresión de las cláusulas del contrato. El pensamiento judeocristiano busca construir una nueva comunidad fraterna cuya ley sea el amor. El cristianismo apela a una generosidad, no solo al cumplimento de una norma. Las relaciones sociales han de estar estructuradas, no solo en cuanto a justicia, sino en cuanto a relaciones fraternas.

En Aristóteles, no todos los miembros de la sociedad son iguales, hay que tratar igual a los iguales y desigual a los desiguales. En Rawls, todos son iguales y los menos favorecidos han de ser considerados para recibir beneficios. En el pensamiento judeocristiano, 
todos los seres humanos son iguales, gozan del mismo estatus. La construcción de las relaciones sociales se origina en la idea de fraternidad, todos son hijos de Dios.

Los proyectos de Aristóteles y Rawls son explícitamente reflexiones filosóficas, éticas y políticas para la construcción de una sociedad. El cristianismo y la Iglesia hacen una reflexión desde la fe, en la que la construcción de la sociedad no es un fin en sí mismo, sino un medio para un conseguir un fin religioso.

La política es el instrumento para estructurar la sociedad. Si el Reino de Dios ha de construirse y cambiar las estructuras sociales y la política es la disciplina que busca construir una sociedad, entonces el cristiano para construir el Reino de Dios ha de usar las herramientas de la política.

Aceptar la invitación de Jesús a construir el Reino es ser un artífice de una nueva sociedad, unos cielos nuevos, una tierra nueva, más igualitaria, más justa. El cristianismo está intrínsecamente unido a la política. La praxis cristiana es praxis política. Creer es esperar construyendo en el amor. La praxis política está en función del Reino. No es una política para conseguir el poder, es una acción para construir una sociedad que posibilite el desarrollo del ser humano, el punto de partida es la igualdad de los seres humanos y el derecho a desarrollarse en una sociedad como tal.

Seguir a Jesús es actuar construyendo el Reino. Ser cristiano es ser político, es buscar activamente edificar una sociedad que considera que el otro es de la misma condición, es igual que yo, ni más ni menos. Ser cristiano es buscar la creación de estructuras sociales que posibiliten generar condiciones para el desarrollo de todos sus miembros, de acuerdo con esa dignidad de ser hijos de Dios.

Si el cristiano ha de ser político para construir el Reino, ¿̇hay indicios de que este ideal, en los dos milenios de cristianismo se haya concretado en una sociedad? La respuesta a esta pregunta rebasa con mucho la extensión de este artículo, al inicio se planteó la pregunta: ¿La política construye el Reino de Dios? En los documentos revisados, se encuentra que el Reino es un proyecto que pasa necesariamente por lo político, pero no se limita a ello. La política es un medio para concretizar el Reino en la dimensión espacio-temporal. Es un proyecto desde la fe que espera construyendo unos cielos nuevos, una tierra nueva en el amor. Queda pendiente la pregunta: ¿Las semillas del Reino han germinado? ¿Dónde?

\section{Referencias}

Aristóteles (1985). Ética nicomáquea. Política. México: Porrúa.

Beuchot, M. (2009). Tratado de hermenéutica analógica: hacia un nuevo modelo de interpretación (2. ${ }^{\mathrm{a}}$ ed.). México: Universidad Nacional Autónoma de México.

Beuchot, M. (2014). Exposición sintética de la hermenéutica analógica. En B. Solares (ed.), Actualidad de la hermenéutica analógica (pp. 35-62). México: Universidad Nacional Autónoma de México. 
Beuchot, M. (2015). Elementos esenciales de una hermenéutica analógica. Diánoia, $60(74), 127-145$.

Constitución pastoral Gaudium et spes: Sobre la iglesia en el mundo actual. Recuperado de http://www.vatican.va/archive/hist_councils/ii_vatican_council/ documents/vat-ii_const_19651207_gaudium-et-spes_sp.html

El Libro del Pueblo de Dios: La Biblia (1992). Buenos Aires: Paulinas.

Ferraris, M. (2004). La hermenéutica. Madrid: Cristiandad.

Habermas, J. y Rawls, J. (1998). Debate sobre el liberalismo político. Barcelona: Paidós.

Pontificio Consejo “Justicia y Paz” (2005). Compendio de la doctrina social de la Iglesia. Lima: Paulinas.

Rawls, J. (1985). Teoría de la justicia. México: Fondo de Cultura Económica.

Rawls, J. (1996). Liberalismo político. México: Fondo de Cultura Económica.

Rawls, J. (2002). La justicia como equidad: una reformulación. Barcelona: Paidós.

Ricoeur, P. (1980). La metáfora viva. Madrid: Cristiandad. 